Research Paper:

\title{
The Effectiveness of Humor Training on Happiness and Life Satisfaction of Female Patients With Epilepsy
}

\author{
Nazanin Bagherzadeh Shirvan' ${ }^{1}$, Anahita Khodabakhshi-Koolaee ${ }^{2^{*}}$ (D) \\ 1. Department of Counseling, Faculty of Humanities and Social Sciences, Science and Research Branch, Islamic Azad University, Tehran, Iran \\ 2. Department of Psychology and Education Sciences, Faculty of Humanities, Khatam University, Tehran, Iran.
}

\begin{tabular}{|c|c|}
\hline $\begin{array}{l}\text { Use your device to scan } \\
\text { and read the article online }\end{array}$ & Cteat on: Bagherzadeh Shirvan, N. \& Khodabakhshi-Koolaee, A. 2021. The Effectiveness of Humor Training on Happiness \\
\hline Q & $\begin{array}{l}\text { and Life Satisfaction of Female Patients With Epilepsy. Journal of Client-Centered Nursing Care, 7(4), pp. 255-262. https://doi. } \\
\text { org/10.32598/JCCNC.7.4.33.17 }\end{array}$ \\
\hline atsent & dol https://doi.org/10.32598/JCCNC.7.4.33.17 \\
\hline
\end{tabular}

\section{(1) (3)}

Article info:

Received: 27 Jul 2021

Accepted: 12 Sep 2021

Published: 01 Nov 2021
Keywords:

Humor, Happiness, Satisfaction, Epilepsy, Women

\begin{abstract}
A B S T RA C T
Background: Women with epilepsy face many physical and psychological problems due to their illness. Epilepsy affects women's motherhood, parenting role, and quality of life. Thus, in addition to medical interventions, their recovery programs should also cover psychological therapies. Accordingly, this study aimed to examine the effectiveness of humor training on happiness and life satisfaction of female patients with epilepsy.

Methods: This study was conducted using a quasi-experimental method with a pretest-posttest design and control group. The research population included all female patients who were members of the Iranian Epilepsy Association, Tehran, in 2020. The subjects were selected using convenience sampling. To this end, 30 women who met the inclusion criteria were randomly assigned into the intervention $(\mathrm{n}=15)$ and control $(\mathrm{n}=15)$ groups. The intervention group attended eight 2-hour humor training sessions and the control group did not receive any training. The Oxford Happiness Questionnaire and the Satisfaction with Life Scale (SWLS) were completed by the subjects before and after the intervention. The collected data were analyzed by one-way Analysis of Covariance (ANCOVA) using SPSS 24.
\end{abstract}

Results: According to the findings, the patients who received humor training reported significantly higher levels of happiness and life satisfaction compared to the control group. There was a significant difference between the pre-test and post-test mean scores of happiness (pretest: $38.20 \pm 3.59$; post-test: $45.27 \pm 4.18)(\mathrm{F}=26.37 ; \mathrm{P}=0.001)$ and also, there was a significant difference between the mean scores of pre-test and post-test of life satisfaction (pre-test: 13.01 \pm 6.16 ; post-test: $18.67 \pm 5.70)(\mathrm{F}=30.07 ; \mathrm{P}=0.001)$ in the intervention group. This difference was not significant in the control group $(\mathrm{P}>0.05)$.

Conclusion: Humor training increased happiness and life satisfaction among women with epilepsy. This low-cost and easy-to-implement training is recommended to be used by psychologists and psychiatric nurses as a non-pharmacologic alternative along with other treatment options.

\footnotetext{
" Corresponding Author:

Anahita Khodabakhshi-Koolaee, PhD.

Address: Department of Psychology and Education Sciences, Faculty of Humanities, Khatam University, Tehran, Iran. Tel: +98 (21) 89174119

E-mail:a.khodabakhshid@khatam.ac.ir
} 


\section{Highlights}

- Epilepsy is a chronic disease and a common disorder that occurs as recurrent seizures. Psychological and social stresses affect the recurrence of epilepsy.

- Research on women's epilepsy is important because it affects their hormonal changes, pregnancy, breastfeeding, and quality of life.

- The humor training program is a positive psychologic intervention, which reduces psychological distress and improves the quality of life through happiness.

- According to the findings of this study, the female patients reported high levels of happiness and life satisfaction after participating in eight sessions of humor training.

\section{Plain Language Summary}

The humor training program is a positive psychological intervention that is used to treat many physical and mental illnesses. It has been shown that humor can help reduce anxiety, depression, death anxiety, and adjustment to disorders and chronic pain in adults and older adults. Also, humor helps to create moments of joy and positive emotions. The results of this study indicated that the life satisfaction and happiness of women with epilepsy increased after eight sessions of humor training.

\section{Introduction}

pilepsy is a chronic and common disorder that occurs as recurrent seizures in $3 \%$ to $5 \%$ of different populations worldwide (Jameson et al. 2018). The prevalence of epilepsy in Iran is estimated to be about $1 \%$, and near 840,000 people currently have active epilepsy. From the whole population of people with epilepsy in Iran, about 168,000 have Idiopathic Generalized Epilepsy (IGE) (Asadi-Pooya \& Simani 2021). This is a common neurological disorder that may complicate women's reproductive health and lead to increased delivery complications in the mother and the neonate (Melikova Bagirova \& Magalov 2020). There are more than one million women with epilepsy in the United States. Fertile years of pregnancy can be challenging for this population. It has been shown that children born to these women are exposed to an increased risk of major congenital anomalies, lower intelligence quotient scores, and neurodevelopmental disorders when the mother is undergoing anticonvulsant therapy medications (Spiegel \& Merius 2020).

Unpredictable seizures cause these patients to face various psychological and social pressures (Mula \& Sander 2016). Because this disease has a profound effect on patients' quality of life, it causes problems that go far beyond the disease itself (Melikova, Bagirova \& Magalov 2020). People with an innate predisposition to epilepsy are more likely to have seizures in response to stimuli (Ablah et al. 2014), including external and internal stimuli, such as drug use, drug deprivation, cyclic hormonal changes, metabolic disorders, or emotional disorders. If these problems are left uncontrolled, recurrent seizures can reduce the quality of life and satisfaction of epileptic patients and their family members (Schuele 2019). Epilepsy also affects a wide range of psychological and individual functioning. Thus, people with epilepsy are strongly affected by the social and psychological aspects of the disease caused by the seizures. Studies have shown that epileptic patients have lower annual income, lower quality of life and life satisfaction, lower levels of education, and less self-confidence and happiness compared to other people (Ablah et al. 2014).

Happiness refers to a set of pleasures with the absence of pain and the maximum combination of positive emotion with the least negative affectivity (Andersson 2008). Happiness leads to positive attitudes toward life, positive self-concept, mental health, emotional balance, hope for the future, a desirable and satisfying attitude towards self and others, balanced social relationships, avoidance of resentment and hatred, conscious choice of life goals, more attempts to achieve goals, avoidance of wasting time and procrastination, increased life success, higher quality of life, better immune system performance against stress and illness, better sleep, more willingness to help others, higher academic achieve- 
ment and job performance, and better decision-making skills (Luhmann et al. 2016). Although happiness cannot restore health in the face of a serious problem, it can improve life expectancy and reduce the severity of illness (Cohn et al. 2009).

Life satisfaction is one of the determinants of health (Vaughan, Mulcahy \& Fitzgerald 2020). The assessment of life satisfaction in health care systems is important because this concept fully interacts with health and there is a close relationship between physical and mental health and life satisfaction (Parra-Rizo \& Sanchis-Soler 2020). Life satisfaction is one of the important variables that is affected by chronic diseases. It is associated with a person's understanding of life situations and is influenced by the culture and value systems, goals, expectations, and concerns of the individual (de Climens et al. 2015). Besides, life satisfaction is the most important component of mental well-being that is associated with assessing the quality of life based on individual criteria, i.e. high life satisfaction is a state, in which the conditions perceived by the individual corresponding to the norms set by him (Polonsky et al. 2015).

People with epilepsy suffer from a variety of social and psychological problems due to their illness. Thus, in addition to medical interventions, their recovery programs should also cover psychological interventions, such as humor training. Humor is an advanced defense mechanism that helps people, especially those with illnesses, such as epilepsy, cope with emotional conflicts or external stressors by focusing on humorous and entertaining activities (Tagalidou et al. 2019).

Humor, as part of positivist psychology, has a wide range of meanings. Humor has been defined as differences in a person's behaviors, experiences, emotions, feedback, and abilities in terms of entertainment, laughter, wit, etc. (Osincup 2020). In addition to its physical effects, humor is associated with many psychological benefits. Probably the most obvious positive emotional state of humor and laughter that can be seen on people's faces is happiness (Ulloth 2002). People who have a greater sense of humor are more likely to express their problems and try to alleviate their grief by supporting others in their daily problems, which makes them enjoy interacting with others more and feel more competent (Lovorn 2008). It has been shown that humor training is effective on happiness (Wellenzohn, Proyer \& Ruch 2018), relieving chronic pain and increasing happiness in adults with chronic pain (Tes et al. 2010), life satisfaction (Mathieu 2008), sexual satisfaction (Khodabakhshi-Koolaee \& MirAfzal 2017), perceived stress, depression, anxiety, and psychological well-being (Tagalidou et al. 2019).
Due to the psychosocial problems that these patients experience and considering that women, especially in their reproductive years, are more affected by the negative aspects of this disease, this study seeks to provide a psychological approach to reduce the psychological and social distress caused by this disease through humor intervention. Accordingly, the aim of this study was to determine the effectiveness of humor training on happiness and life satisfaction of female patients with epilepsy.

\section{Materials and Methods}

The present study was conducted using a quasi-experimental method with a control group and a pretest-posttest design. The research population included all epileptic women $(n=356)$ as members of the Iranian Epilepsy Association, Tehran, in 2020. The initial subjects were selected using, voluntary, and convenience sampling. The inclusion criteria were: (1) age 25 to 40 years, (2) being married, (3) and no other serious physical and mental illness other than epilepsy diagnosed by the association physician. The exclusion criteria were simultaneous participation in individual and group counseling and psychotherapy sessions and the absence of more than two training sessions. To this end, after obtaining the consent of the officials of the Epilepsy Association and the patients, the Oxford Happiness Questionnaire and the Satisfaction with Life Scale (SWLS) were administered to 144 eligible patients. Of 58 patients who scored one standard deviation lower than the mean, 30 persons (on the basis of $\mathrm{G}^{*}$ power) who met the inclusion criteria were randomly assigned into the intervention and control groups, each with 15 subjects.

The Oxford Happiness Questionnaire: This questionnaire was developed by Hills and Argyle (2002) to measure happiness and contains 29 items. Each item has 4 choices ranging from 0 to 3 ; thus, the maximum score of the questionnaire is 87. A higher score indicates a higher level of happiness. Hills and Argyle (2002) evaluated the reliability of this questionnaire using $347 \mathrm{sub}$ jects and obtained a Cronbach's alpha of 0.90. Besides, Alipoor and Noorbala administered the Persian version of the questionnaire to 132 students and estimated its reliability coefficient using Cronbach's alpha as 0.93 (Alipoor \& Noorbala 1999). The questionnaire was administered to the subjects in this study and its reliability was 0.94 using Cronbach's alpha.

The Satisfaction with Life Scale (SWLS): This fiveitem scale was designed to measure overall life satisfaction (Diener et al. 1985). Answers to the items are scored on a 5-point Likert scale ranging from completely satis- 
fied (5) to completely dissatisfied (1). The authors administered the scale to a sample of 176 undergraduate students and reported the test-retest correlation coefficient of $r=0.82$ after two months and the Cronbach's alpha coefficient of 0.87 (Diener et al. 1985). Jahangiri Zadeh and Khodabakhshi Koolaee (2016) assessed the Persian version of the scale and reported its reliability index by Cronbach's alpha coefficient as 0.87 .

\section{Procedure}

Before conducting the study, a written permit was obtained from the University Ethics Committee and the necessary arrangements were made. Besides, informed written consent was obtained from the subjects and they were assured that their transportation costs would be paid by the researcher. The training sessions for the intervention group were held for 8 weeks on Tuesdays and Thursdays in a hall prepared for this purpose. Each session was held in the morning and lasted about 120 minutes.

After administering the pretest, the members of the intervention group attended 8 humor training sessions (one 2-hour session per week) for 2 months based on the 7 Humor Habits Program proposed by McGhee (2010) and the protocol provided by Martin and Ford (2018) (Table 1). The members of the control group did not receive any training. The training sessions were conducted by the supervisor of the Master of Rehabilitation Counseling student of the research group. At the end of the sessions, both groups completed the questionnaires again. The flow diagram of the study process is shown in Figure 1.The collected data were analyzed using SPSS 24. One-way Analysis of Covariance (ANCOVA) was run to examine the changes in the participants' happiness and life satisfaction before and after the intervention.

\section{Results}

The Mean \pm SD age of the subjects was $(34.03 \pm 5.25)$ years $(\mathrm{P}>0.05)$. Table 2 shows the descriptive statistics for happiness and life satisfaction in the intervention and control groups in the pre-test and post-test stages. There was no difference in mean values in the two groups before the intervention.

To check the assumptions of ANCOVA, the ShapiroWilk test was run and the results confirmed the normality assumption of the research variables in the sample because the calculated $\mathrm{z}$-scores were not significant $(\mathrm{P}>0.05)$. Moreover, the analysis of collinearity for happiness and life satisfaction showed that the collinearity was not violated. The analysis of the regression slope homogeneity showed that because the F-values for happiness $(\mathrm{F}=0.019)$ and life satisfaction $(\mathrm{F}=5.822)$ were not significant $(\mathrm{P}=0.891$ and 0.078$)$, it can be suggested that the assumption of regression slope homogeneity was established for these variables. Finally, Levene's test of homogeneity of variance showed that the assumption

Table 1. The protocol for the humor training sessions (Martin \& Ford 2010)

\begin{tabular}{|c|c|c|}
\hline Sessions & Outline of the Program & Content \\
\hline 1 & $\begin{array}{l}\text { Introducing the group members } \\
\text { and the group rules }\end{array}$ & $\begin{array}{l}\text { Discussing the concept of humor and the benefits and necessity of learning this skill } \\
\text { as a positive defense mechanism and its impact on social interactions, physical and } \\
\text { mental health, and resistance to everyday life stressors }\end{array}$ \\
\hline 2 & $\begin{array}{l}\text { Identifying the members' unique } \\
\text { style of sense of humor }\end{array}$ & $\begin{array}{l}\text { Discussion, Questions and Answers, role modeling, and behavioral exercises, such as } \\
\text { imaginatively funny conversations with another person and doing the necessary exercises }\end{array}$ \\
\hline 3 & Laughing exercise & $\begin{array}{l}\text { Group discussions, activating the inner child, and ten minutes of laughter for no } \\
\text { reason and without expressing feelings }\end{array}$ \\
\hline 4 & $\begin{array}{l}\text { Developing the skill to play with } \\
\text { words (puns) and telling jokes }\end{array}$ & $\begin{array}{l}\text { Applying techniques, such as playing with words, telling jokes and riddles, teaching } \\
\text { special humor skills, using alternative words in newspaper and bulletin headlines, } \\
\text { imitating comedians' words and sounds, and ten minutes of laughing for no reason } \\
\text { and without expressing feelings }\end{array}$ \\
\hline 5 & $\begin{array}{l}\text { Conscious search for humor in } \\
\text { everyday life }\end{array}$ & $\begin{array}{l}\text { Taking notes of any funning events, sharing hilarious experiences with others, role } \\
\text { modeling, and laughing for ten minutes for no reason and without expressing feelings }\end{array}$ \\
\hline 6 & Learning to laugh at oneself & $\begin{array}{l}\text { Drawing one's caricature, laughing at each other, practicing coping with group } \\
\text { games, and laughing for ten minutes for no reason and without expressing feelings }\end{array}$ \\
\hline 7 & $\begin{array}{l}\text { Telling jokes in the peak of stress } \\
\text { and discomfort }\end{array}$ & $\begin{array}{l}\text { Discussing humorous style in stressful situations, teaching patterns of using humor } \\
\text { in these situations to the members, and doing cognitive exercises }\end{array}$ \\
\hline 8 & Summing up and sharing experiences & $\begin{array}{l}\text { Applying the skills learned during the training sessions, examining their impact, sum- } \\
\text { marizing the training program, introducing several fun websites and assessing their ef- } \\
\text { fects on the group members, and evaluating the effectiveness of the training program }\end{array}$ \\
\hline
\end{tabular}




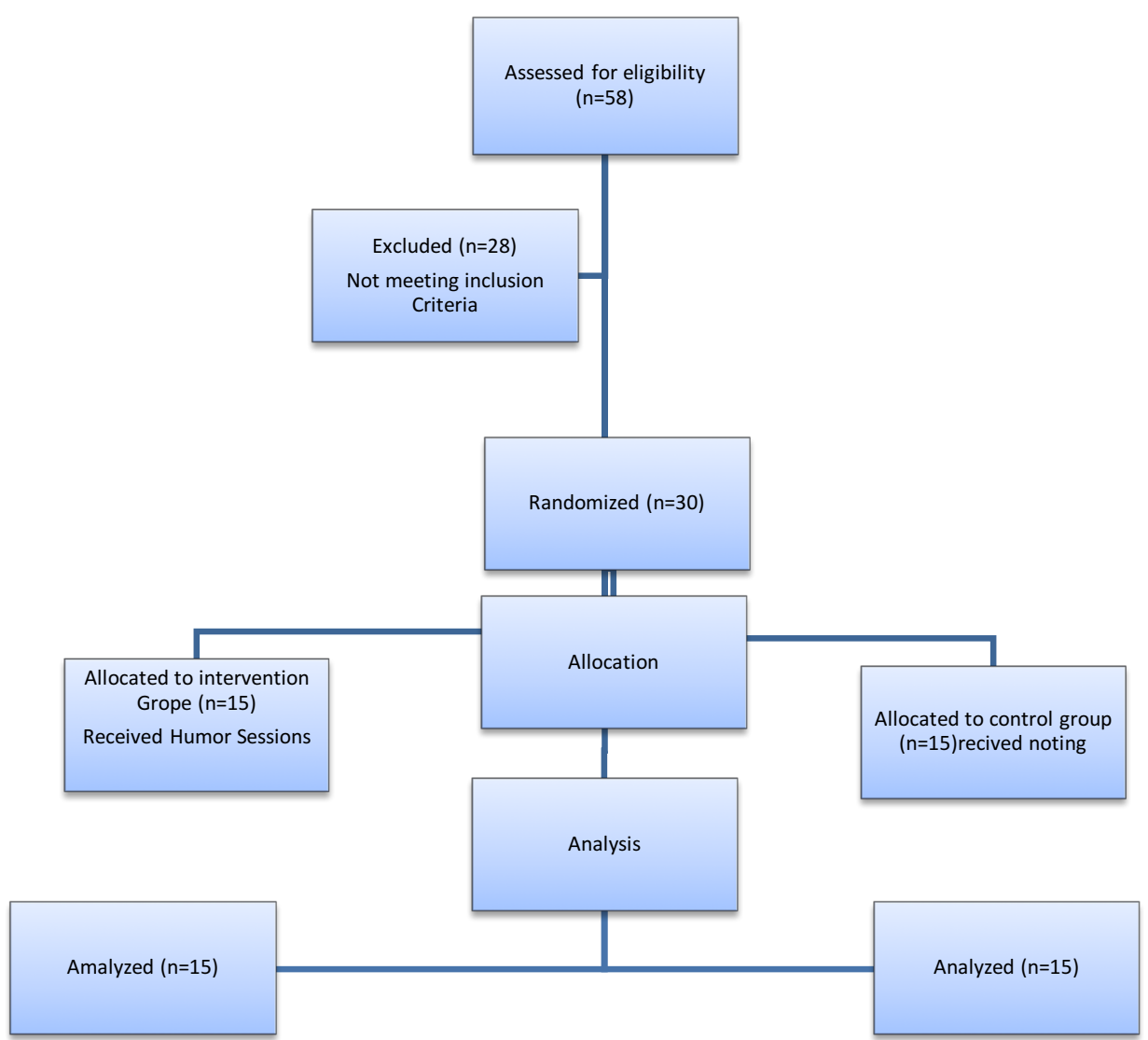

Figure 1. The flow diagram of the study

Client- Centered Nursing Care

of variance homogeneity was also met for the research variables $(\mathrm{P}>0.05)$.

The ANCOVA was run to compare the mean scores of happiness and life satisfaction for the two groups in the post-test. The pre-test scores were controlled as a covariate and then, the post-test scores were compared. To compare the post-intervention mean scores of happiness and life satisfaction, after controlling the effect of the pre-test, ANCOVA was run, the results of which are presented in Table 3 (for happiness) and Table 4 (for life satisfaction):
As can be seen, after adjusting the pre-intervention scores, there was a significant difference between the two groups in terms of the level of happiness $(\mathrm{F}=26.37$; $\mathrm{P}=0.001$ ), confirming the effectiveness of humor training on the happiness of epileptic female patients. Besides, the value of the impact factor showed that $62 \%$ of the intergroup differences in the happiness scores on the post-test were related to the effect of humor training.

As can be seen in Table 4, after adjusting the preintervention scores, there was a significant difference between the two groups in terms of life satisfaction ( $\mathrm{F}=30.07 ; \mathrm{P}=0.001$ ), confirming the effectiveness of

Table 2. The descriptive statistics for happiness and life satisfaction

\begin{tabular}{cccc}
\hline Dependent Variables & Groups & Pretest & Mean \pm SD \\
\cline { 2 - 3 } Happiness & & $38.20 \pm 3.59$ & $45.27 \pm 4.18$ \\
\hline Life Satisfaction & Contervention & $36.93 \pm 4.18$ & $36.53 \pm 4.12$ \\
& Intervention & $13.01 \pm 6.16$ & $18.67 \pm 5.70$ \\
\hline
\end{tabular}

Client- Centered Nursing Care 
Table 3. The results of ANCOVA concerning the happiness

\begin{tabular}{cccccccc}
\hline Variable & Groups & SS & df & MS & F & P & Eta (n) \\
\hline & Pre-Test & 6.623 & 1 & 6.623 & & & \\
Happiness & Group & 394.705 & 1 & 394.705 & 26.37 & 0.001 & 0.62 \\
& Error & 411.705 & 27 & 411.705 & & & \\
\hline
\end{tabular}

Client- Centered Nursing Care

Table 4. The results of ANCOVA concerning the life satisfaction

\begin{tabular}{cccccccc}
\hline Variable & Groups & SS & df & MS & F & P & Eta (n) \\
\hline \multirow{2}{*}{ Life Satisfaction } & Pre-test & 2.394 & 1 & 2.394 & & & \\
& Group & 1157.321 & 1 & 1157.321 & 30.07 & 0.001 & 0.53 \\
& Error & 359.688 & 27 & 359.688 & & \\
\hline
\end{tabular}

Client- Centered Nursing Care

humor training on epileptic female patients' satisfaction with life. Moreover, the value of the impact factor showed that $53 \%$ of the intergroup differences in the life satisfaction scores on the post-test were related to the effect of humor training.

\section{Discussion}

The present study showed that teaching humor skills had a positive effect on the happiness and life satisfaction of female patients with epilepsy. It has been found that humor and positive thinking have a positive and significant relationship with resilience against stress in female nurses working in hospitals in Isfahan (KhodabakhshiKoolaee et al. 2019). Yip and Martin (2006) also showed that sense of humor has a positive relationship with emotional intelligence and social competence so that people with a sense of humor have higher emotional intelligence and more social competence compared to people who are not humorous (Yip \& Martin 2006). It has been also found that nursing students with high humor used humor well in their communication with patients and health care workers, resulting in a more positive feeling in their workplace (Flynn 2020). In another study, Falkenberg et al. (2011) showed that laughter and humor can help reduce depressive symptoms in patients with major depression. They also added that depressed patients were able to create better conditions for themselves by using humor as a coping strategy (Falkenberg et al. 2011).

Humor is used as a coping strategy to manage stress. People with less humor experience mood swings and negative life events more than others (McGhee 2010). Humor reduces negative emotional responses including anxiety, depression, and stress in life and leads to a more positive self-image (McGhee 2010; Martin \& Ford 2018).

Sim used humor skills to reduce behavioral problems and increase resilience in children with chronic diseases and found that humor significantly reduces the levels of cortisol, a stress hormone, in these children and helped them to cope with the disease (Sim 2015). In a meta-analysis study, Gonot-Schoupinsky and colleagues examined the effect of laughter and happiness on personal development and self-care skills. They found that laughter and humor have many benefits and applications in medical settings. It also enables patients to take care of themselves and helps them plan programs tailored to their specific needs and goals in life (Gonot-Schoupinsky, Garip \& Sheffield 2020). In general, humor is recommended for all age groups and patients. It has been shown that the elderly who have a better sense of humor report less death anxiety and care more about life (Hosseinzadeh \& Khodabakhshi-koolaee 2017). Humor also has many therapeutic uses in cancer and gives the patient a chance to live again and be resilient (Joshua, Cotroneo \& Clarke 2005).

Humor is more than an emotion, it is a person's perception of life and the problems around him/her. The humor includes positive emotions, such as happiness, joy, hope and positive thinking, and ultimately life satisfaction. Humor also increases the tolerance for failure and decreases physical pain and negative emotions associated with diseases, and ultimately contributes to better selfcare and greater resilience in patients (Martin \& Ford 2018; Flynn 2020). 
The sample in this study consisted of all married women aged 25-40 years with epilepsy in Tehran in 2020. The study was conducted from May to August 2020 after the announcement of the normality of the situation concerning COVID-19 in Tehran. However, with the onset of the second COVID-19 wave, it was not possible to perform a follow-up to evaluate the retention effect of the intervention.

\section{Conclusion}

This study showed that humor training can help increase the happiness and life satisfaction of female epileptic patients. Thus, humor skills training can be used as a low-cost group training method and as non-pharmacological treatment along with other pharmacological interventions in medical centers and hospitals for the treatment and rehabilitation of epileptic patients.

\section{Ethical Considerations}

\section{Compliance with ethical guidelines}

The study was approved by the Research Council of Islamic Azad University, Science and Research Branch, Tehran (Code: IR.IAU.SRB.REC.1399.038). All ethical principles are considered in this article. The participants were informed about the purpose of the research and its implementation stages. They were also assured about the confidentiality of their information. They were free to leave the study whenever they wished, and if desired, the research results would be available to them.

\section{Funding}

The paper was extracted from the MSc. thesis of the first author at the Department of Counseling, Faculty of Humanities and Social Sciences, Science and Research Branch, Islamic Azad University. This research did not receive any grant from funding agencies in the public, commercial, or non-profit sectors.

\section{Authors' contributions}

All authors equally contributed to preparing this article.

\section{Conflict of interest}

The authors declared no conflict of interest.

\section{References}

Ablah, E., et al. 2014. Prevalence of epilepsy in rural Kansas. Epilepsy Research, 108(4), pp. 792-801. [DOI:10.1016/j.eplepsyres.2014.01.001] [PMID]

Alipoor, A. \& Noorbala, A. A., 1999. [A preliminary evaluation of the validity and reliability of the Oxford happiness questionnaire in students in the universities of Tehran (Persian)]. Iranian Journal of Psychiatry and Clinical Psychology, 5(1 And 2), pp. 55-66. http:/ /ijpcp.iums.ac.ir/article-1-1777-en.html

Andresson, P., 2008. Happiness and health, Wellbeing among the self-employes. Journal of Social-Economices, 37(1), pp. 21336. [DOI:10.1016/j.socec.2007.03.003]

Asadi-Pooya, A. A. \& Simani, L., 2021. Epilepsy syndromes in Iran: A systematic review. Acta Neurologica Scandinavica, 143(5), pp. 475-80. [DOI:10.1111/ane.13381] [PMID]

Cohn, M. A., et al. 2009. Happiness unpacked: Positive emotions increase life satisfaction by building resilience. Emotion, 9(3), pp. 361-8. [DOI:10.1037/a0015952] [PMID] [PMCID]

Diener, E. D., et al. 1985. The satisfaction with life scale. Journal of Personality Assessment, 49(1), pp. 71-5. [DOI:10.1207/ s15327752jpa4901_13] [PMID]

Falkenberg, I., et al. 2011. Implementation of a manual-based training of humor abilities in patients with depression: A pilot study. Psychiatry Research, 186(2-3), pp. 454-7. [DOI:10.1016/j. psychres.2010.10.009] [PMID]

Flynn, D., 2020. Personal and social influences on the use of humour in the interactions of student nurses in UK clinical settings. British Journal of Nursing, 29(5), pp. 303-7. [DOI:10.12968/ bjon.2020.29.5.303] [PMID]

Gonot-Schoupinsky, F. N., Garip, G. \& Sheffield, D., 2020 Laughter and humour for personal development: A systematic scoping review of the evidence. European Journal of Integrative Medicine, 37, p. 101144. [DOI:10.1016/j.eujim.2020.101144]

Hosseinzadeh, E. \& AnahitaKhodabakhshi-koolaee, A., 2017. [The relationship between senses of humor and Mindfulness with Anxiety of death in elderly men refer to Jahandidegan center of seven region of municipality in Tehran city (Persian)] Journal of Health Literacy, 2(3), pp. 177-86. [DOI:10.29252/ jhl.2.3.177]

Hills, P. \& Argyle, M., 2002. The Oxford happiness questionnaire: A compact scale for the measurement of psychological well-being. Personality and Individual Differences, 33(7), pp. 1073-82. [DOI:10.1016/S0191-8869(01)00213-6]

JahangiriZadeh, P. \& Khodabakhshi Koolaee, A., 2016. The relationship between self-concept, life satisfaction and hope among retired and housewife older adults' women. Journal of Gerontology, 1(1), pp. 19-28. [DOI:10.18869/acadpub. joge.1.1.35]

Jameson, J. L., et al. 2018. Harrison's principles of internal medicine: The profession of medicine. New York McGraw-Hill Education. https://books.google.com/ books?id=HACWtAEACAAJ\&dq

Joshua, A. M., Cotroneo, A. \& Clarke, S., 2005. Humor and oncology. Journal of Clinical Oncology, 23(3), pp. 645-8. [DOI:10.1200/ JCO.2005.09.064] [PMID] 
Lovorn, M. G., 2008. Humor in the home and in the classroom: The benefits of laughing while we learn. Journal of Education and Human Development, 2(1). https:/ / www.researchgate.net/publication/228665694_Humor_in_the_Home_and_in_the_Classroom_The_Benefits_of_Laughing_While_We_Learn

Khodabakhshi-Koolaee, A., et al. 2019. [Relationship between optimism and humor with resilience in female nurses of hospitals in Isfahan, Iran (Persian)]. Journal of Gorgan University of Medical Sciences, 21(1), pp. 87-93. http://goums.ac.ir/journal/article1-3288-en.html

Khodabakhshi-Koolaee, A. \& Mirafzal, N. S., 2017. [Relationship between humor and social support with sex satisfaction in elderly married women (Persian)]. Journal of Gerontology, 2(1), pp. 1-10. [DOI:10.29252/joge.2.1.1]

Luhmann, M., et al. 2016. Is valuing happiness associated with lower well-being? A factor-level analysis using the Valuing Happiness Scale. Journal of Research in Personality, 60, pp. 46-50. [DOI:10.1016/j.jrp.2015.11.003] [PMID] [PMCID]

Martin, R. A. \& Ford, T., 2018. The psychology of humor: An integrative approach. Cambridge: Academic Press. [DOI:10.1016/ B978-0-12-812143-6.00009-6]

Mathieu, S. I., 2008. Happiness and humor group promotes life satisfaction for senior center participants. Activities, Adaptation $\mathcal{E}$ Aging, 32(2), pp. 134-48. [DOI:10.1080/01924780802143089]

McGhee, P., 2010. Humor as survival training for a stressed-out world: The 7 humor habits program. Bloomington: Author House. https://www.google.com/books/edition/Humor_ the_Lighter_Path_to_Resilience_and/ubiQ8wCrP0IC?hl=en

Melikova, S., Bagirova, H. \& Magalov, S., 2020. The impact of maternal epilepsy on delivery and neonatal outcomes. Child's Nervous System, 36(4), pp. 775-82. [DOI:10.1007/s00381-01904435-2] [PMID]

Mula, M. \& Sander, J. W., 2016. Psychosocial aspects of epilepsy: A wider approach. BJPsych Open, 2(4), pp. 270-4. [DOI:10.1192/ bjpo.bp.115.002345] [PMID] [PMCID]

Osincup, P., 2020. How to use humor in clinical settings. AMA Journal of Ethics, 22(7), pp. 588-95. [DOI:10.1001/amajethics.2020.588] [PMID]

Parra-Rizo, M. A. \& Sanchis-Soler, G., 2020. Satisfaction with life, subjective well-being and functional skills in active older adults based on their level of physical activity practice. International Journal of Environmental Research and Public Health, 17(4), p. 1299. [DOI:10.3390/ijerph17041299] [PMID] [PMCID]

Polonsky, W. H., et al. 2015. Development of a new measure for assessing glucose monitoring device-related treatment satisfaction and quality of life. Diabetes Technology \& Therapeutics, 17(9), pp. 657-63. [DOI:10.1089/dia.2014.0417] [PMID]

de Climens, A. R., et al. 2015. Review of patient-reported outcome instruments measuring health-related quality of life and satisfaction in patients with type 2 diabetes treated with oral therapy. Current Medical Research and Opinion, 31(4), pp. 643-65. [DOI:10.1185/03007995.2015.1020364] [PMID]

Sim, I. O., 2015. Humor intervention program for children with chronic diseases. Applied Nursing Research, 28(4), pp. 404-12. [DOI:10.1016/j.apnr.2015.09.001] [PMID]
Spiegel, R. \& Merius, H., 2020. Principles of epilepsy management for women in their reproductive years. Frontiers in Neurology, 11, p. 322. [DOI:10.3389/fneur.2020.00322] [PMID] [PMCID]

Schuele, S. U., 2019. Evaluation of seizure etiology from routine testing to genetic evaluation. Continuum: Lifelong Learning in Neurology, 25(2), pp. 322-42. [DOI:10.1212/ CON.0000000000000723] [PMID]

Tagalidou, N., et al. 2019. Efficacy and feasibility of a humor training for people suffering from depression, anxiety, and adjustment disorder: A randomized controlled trial. BMC Psychiatry, 19(1), pp. 1-13. [DOI:10.1186/s12888-019-2075-x] [PMID] [PMCID]

Tse, M. M., et al. 2010. Humor therapy: Relieving chronic pain and enhancing happiness for older adults. Journal of Aging Research, 2010, p. 343574. [DOI:10.4061/2010/343574] [PMID] [PMCID]

Ulloth, J. K., 2002. The benefits of humor in nursing education. Journal of Nursing Education, 41(11), pp. 476-81. [DOI:10.3928/0148-4834-20021101-06]

Vaughan, B., Mulcahy, J. \& Fitzgerald, K., 2020. PROMIS® General Life Satisfaction scale: Construct validity in musculoskeletal pain patients. Chiropractic \& Manual Therapies, 28(1), p. 27. [DOI:10.1186/s12998-020-00320-x] [PMID] [PMCID]

Wellenzohn, S., Proyer, R. T. \& Ruch, W., 2018. Who benefits from humor-based positive psychology interventions? The moderating effects of personality traits and sense of humor. Frontiers in Psychology, 9, p. 821. [DOI:10.3389/fpsyg.2018.00821] [PMID] [PMCID]

Yip, J. A. \& Martin, R. A., 2006. Sense of humor, emotional intelligence, and social competence. Journal of Research in Personality, 40(6), pp. 1202-8. [DOI:10.1016/j.jp. 2005.08.005] 